\title{
'Driven in a Cart Pulled by Elephant and Horse Together' - the Perception of Government School Teachers about their Capacity Building through Public-Private Partnership
}

\author{
Sujata Deshpande \\ Symbiosis International University \\ Pune city, India \\ Jyoti Chandiramani \\ Symbiosis International University \\ Pune city, India
}

\begin{abstract}
Abstact. The purpose of this study is to identify the relevance and adequacy of capacity building initiatives from government school teachers' point of view. The enrolment of students in government schools in India is dwindling due to poor teaching-learning practices and so to enhance the quality of education and supplement government's efforts in capacity building of teachers a unique public private partnership (PPP) based teacher mentor program has been initiated at Pune city in India. The data collected from both the survey and in-depth interview of fifty government school teachers were analyzed through framework approach to identify teachers' perceptions on A) what according to them is effective capacity building, B) the perceived strengths and weaknesses of the ongoing PPP based training and C) their suggestions on the way forward. The findings reveal the deeper reasons for sub-optimal results despite the best intentions from both government and private partners. Metaphorically inferred, the PPP based capacity building is like an elephant and a horse pulling a cart together. Where 'Elephant' denotes the large, powerful yet bureaucratically slow placed government school system and 'Horse' represents the goals driven and fast-paced external (PNGE) specialist/ catalyst. The researchers hope that the insights from teachers' 'voices' will help optimize the outcome envisaged by the PPP, and the findings will foster the advocacy for deep-rooted policy changes.
\end{abstract}

Keywords: Capacity building; Government school teachers; PPP; teacher perceptions; teaching-learning practices 


\section{Introduction}

The government school teachers of India are at crossroads of expectations. There is extensive research highlighting the urgency for the teachers across the globe to revamp their existing practice to meet the complex learning needs of twentyfirst-century students (e.g., Cole and Knowles, 2000; Bolam, 2002; DarlingHammond, 2009). In the context of India, age-appropriate reading and numerical skills are lacking in students from government schools pointing towards ineffective teaching-learning practices that call for improvement. Also, various studies point out that since India is poised to witness a huge demographic dividend, strengthening the foundation of students is necessary (e.g. Rath, S. K., \& Bhagavan, B. 2014; Contractor, F. J., Kumar, V., \& Dhanraj, C. 2015; James, K. S. 2008). Therefore, to enhance the capacity of school teachers, inservice training programs mandated by the centre and state governments are periodically conducted by DIETs. Despite a spate of successive education policy reforms in the last decade (see notes, NCF1; NUEPA2; ${ }^{2}{ }^{2} E^{3}$ ), the dismal PISA ${ }^{4}$ performance of India and the more recent results ofASER ${ }^{5}$ survey indicate that only $44.2 \%$ of standard five students from government schools can read the grade two level text. To strengthen the government's effort, the PNGEs are also supporting in the government schools. For this study, one unique PPP between municipal (local) government and PNGE, for capacity building of vernacular (Marathi) medium school teachers are selected. Through this PPP, an internal cadre of teacher mentors has been identified and systematically developed since 2017, and these mentor teachers, in turn, train the 1300 teachers. The purpose of this study is to understand the perceived relevance of PPP based capacity building, by the teachers.

\section{Review of Literature}

For this study, a review of literature is conducted by authors to understand the emerging views on the capacity building of teachers.

\subsection{Changing expectation from twenty-first-century teachers and their professional development}

As aptly quoted, "To solve the learning crisis, all children must have teachers who are trained, motivated and enjoy teaching, who can identify and support weak learners, and who are backed by well-managed systems" (UNESCO, 2013, p. 30). There has been an extensive literature on the changing expectations from the teacher while stepping into the new millennium. Bransford et al. (2005) observed that only capable and competent teachers would be able to demonstrate the resilience to incorporate new pedagogy and knowledge required in the changing times. Bransford further added that teachers need to be aware that their day to day decisions have a significant and transformative impact on student's long term development as each student is unique in terms of his or her context, language, culture, personality as we move more towards inclusive learning. The approach towards teaching must be child-centric and embrace diversity. Similarly, Turner- Bisset (2001) highlighted that to have the 
upper hand in the teaching profession; the teachers need to continue their upgradation of knowledge and skills and apply their practice in classrooms.

The impact of quality inputs from teachers in catapulting students learning has been accepted and widely emphasized upon in literature (Hammerness et al. 2005; Darling Hammond, 2009).Researchers also emphasize that capacity building programs cannot be considered ineffective if they do not result in enhanced student learning outcomes(e.g., Shymansky et al. 2001; Fletcher et al. 2002; OECD, 2005). OECD study elaborates that in a complex school environment, many factors affect students learning and not just teaching inputs. The demanding nature of the job, high expectations from the teachers to be prepared to face the needs of 21st-century learners are highlighted through a large number of scholarly articles highlighting the importance of adaptivity and integration of nuances in teaching-learning (Cole \& Knowles,2000; Darling Hammond, 2009). Given the vast and fast-paced changes in education today, there is a shift in teachers' roles from the positivist approach (Snape \& Spencer, 2003), which promotes the transfer of knowledge to the constructivist paradigm (Ormston et al., 2014), where a teacher is a facilitator to students in co-creating their meanings. It is, therefore, crucial for teachers to not stagnate and keep enhancing their repertoire of pedagogy and content. However, it is not enough for teachers to know and actively seek what they need to learn without a supportive environment and an equally change savvy education system. European Commission (2000, p. 40) asks a pertinent question that while teachers are facing demands to evolve with huge expectations from them to transition and become "multifaceted" do they have matching capacity building support or experience to adapt and cope with this new wave of change. Menter et al. (2010) aptly point out that the main themes of the educational debates across countries are around "positioning" and "ownership" of teacher education. From the systemic nexus who onus is capacity building of teachers is important for the successful teacher development. Collinson et al. (2009) point out that in the highly interconnected world with enormous interdependencies, teacher learning through continuous and ongoing learning is viewed with importance today. In their article, they highlight glocalization, mentoring, and teacher evaluation as evolving themes in different countries. In their critical analysis of what makes professional development effective. Garret et al. (2001) who studied a national sample of teachers, claim that the contemporary professional capacity development of teachers is planned to ensure sustainable learning over time. Researchers agree that only concentrating on content, facilitation skills and methodology is not enough to ensure effective professional development. As stated by Webster- Wright, A. (2009), the ongoing methods of planning professional development for teachers do not focus on actual learning outcomes instead they focus on delivery, methodology and evaluation. As noted by Kirby et al. (2006), the professional development of teachers is more "exaggerated wordiness and lofty ideas" which lack objectivity. Commenting on the need and scope of teacher professional development amid educational reforms. Little, J. W. (1993) states that effective Professional development (PD) should lead to a useful association of thoughts and practices among colleagues, even outside the context of the classroom. It should not be one pill panacea to all requirements. It 
should allow for 'informed dissent.' It should be learner-centric and help them employ ability and grow. It should promote 'inquiry' and finally, Little argues that there should be bureaucratic non -interference. Thus, the literature points out to an enhanced focus and interest in expectations from teachers and their corresponding professional development.

\subsection{Professional development of government school teachers in India}

Teacher education reforms are not new to the Indian education system. Even the Education Commission (1964), professed professionalization in training the teachers through comprehensive colleges and interlinked programs, among many other recommendations. Subsequently, NPE (1986) also acknowledged that the teacher education scenario was far from satisfactory and emphasized on revamping both the pre-service and in-service training. NCF (2009) highlighted that insufficient training of teachers and their inability to equip the learning needs is one of the reasons for the educational crisis along with the disconnected and incoherent curriculum. NCF further pointed out that teacher training and school education have a 'symbiotic relationship,' and without looking at both in totality, the quality of the education system cannot be improved. For teacher training, the policy recommendation included twenty-one days in-service training, conferences, professional fora, resource room, faculty visits exchange and fellowship. NUEPA (2014), Annual report which also documents the summary of their research studies conducted on its different states of India, admitted that "education planning in India is yet to be professionalized and made result-oriented" not merely a "compliance exercise to access funds" from the federal government. NPE (2016), pointed out that the poor quality of education in schools was directly linked with the poor quality of teaching inputs as the teacher education was not up to the mark. NPE (2016), states that teachers with low academic achievement and inadequate pre-service training get appointed as school teachers. Though there have been several successive policy regulations to improve the capacity of the school education system, even the recent draft NPE (2019) also points out the need to "reconfigure, transform and reinvigorate" the education system. Therefore, in a nutshell, if one looks at the comprehensiveness of the thought process of policymakers towards teacher education, it is highly commendable, however, ironically most of the studies reveal that there are many challenges in the implementation at the ground level. Batra, P (2009), observes that a lot of government resources are spent on "motivating" teachers who have a weak academic foundation, and therefore the author denotes them as "poorly qualified" through "piece-meal in-service training" without taking into consideration the actual need of millions of teachers. Clearly, in this case, 'motivation' given to teachers is a waste of time as what limits them is a skill issue and not a will issue. It does not, however, mean that all the government school teachers are in-efficient in delivering quality inputs; in fact, some of them are highly experienced and adept in their practice, and therefore it is equally important to provide them with specific and needbased learning opportunities to develop further. As opined by Anuradha De et al. (2005) in their study, "...parents face a difficult choice between low quality and no quality at the primary level." 
The study of the literature reveals that in India, only a few researchers including Batra, P (2009), highlight the importance of teacher's voice stating that there is not enough seriousness at the policy level to cull out their felt relevance about such interventions. The paper is an attempt to surface teachers' voices on their capacity building. To bridge this gap, there has been increasing support provided to government schools by Corporate Social responsibility (CSR) funders, private philanthropists, and NGOs. For the ease of understanding in this paper, we would refer to all the non -government supporters as private nongovernment entities (PNGEs). Though the PNGEs bring expertise and quality, they do not have the advantage of scale and bandwidth. For this study the researchers selected a unique PPP partnership between the local government and PNGE, to internally build the capacity of teachers by developing a cadre of teacher mentors. The teacher mentors are selected from among the existing government school teachers based on the pre-specified criterion and further trained by experts through PNGEs support and in turn, are expected to train and coach the teachers in their respective clusters through a structured approach to build their capacity. The city is divided into fifteen clusters each with twenty to thirty government schools on an average depending on the area. The purpose of our study is on teachers' perceptions of their professional development (Bolam, 2002).Our objective is to enquire from the teachers 'ex-post' (that is after attending both DIET training and PPP based training) periodically during 201719 on vernacular (Marathi) language reading fluency about the following:

1) What are the components of effective capacity building for teachers?

2) What are their perceived strengths and challenges of PPP based program?

3) What are their suggestions for way ahead?

\section{Research Design}

\subsection{Sample}

The researchers conducted in-depth inquiry from teachers who have attended both government training and PPP training, which is based on a partnership between municipal (local) government and PNGE during 2017-19, while the government training is also conducted per the mandate of Centre and State government through DIET periodically. The study focused on vernacular (Marathi) medium schools where through both the initiatives, how to teach reading of Marathi language was trained to teachers. The government schools are divided into fifteen area clusters with an average of twenty to thirty schools in each and a total of 1300 primary school teachers from Marathi medium schools. Out of these, a random sample of fifty teachers was selected. The basis of selection was a random selection from those who had in the academic year 2017-18, attended both 'DIET training' and 'PPP based training' simultaneously, and were permanent teachers (not contract teachers). The purpose of choosing vernacular (Marathi) medium schools was that in recent times the effort towards capacity building of teachers to improve the teaching-learning practices in these 
schools has increased, given the dwindling enrollment of students and move towards private schools.

\subsection{Methodology}

The qualitative study has been conducted with fifty randomly selected municipal school teachers from 15 clusters in a large city in Maharashtra, India. Since it was carried out in government schools, a due letter of permission was sought from the Education Department of the municipal (local) government. To avoid bias from the result both online survey and in-depth interviews were conducted to bring out deeper meanings and perceptions from the teachers.

\subsection{Data Collection and Analysis}

First, the dipstick understanding of the teachers' perception was garnered from the survey which was followed by an in-depth interview of teachers at preagreed time and place in school. Additionally, the key stakeholders were interviewed to understand their role in design, delivery or implementation of capacity building interventions including DIET trainers, education officers, PPP trainers, NGO representatives, and school Headmasters. Their view was important for a holistic interpretation through data triangulation for qualitative analysis. As aptly stated by Taylor and Bogdan (1998:7), the qualitative research "produces descriptive data on people's own written or spoken words and observable behavior." Most of the teachers taught in $3^{\text {rd }}$ to $8^{\text {th }}$ standard. The qualification of $80 \%$ of the teachers interviewed was D.Ed. and only $20 \%$ had B.Ed. or M.Ed. qualification. The approval letter from the Education officer helped galvanize the research process as teachers are government servants and without prior permission, no one is authorized to interview them. Audio or video recording was strictly prohibited therefore interviews were conducted in the Marathi language and captured by the researcher verbatim through notes and then translated in English on excel sheets. The instrument was based on essential information questions recording gender, educational qualification, days and type of training attended, etc. along with the questions asked on research objectives, the instrument was piloted to check the ease of comprehension, modified, and the content was validated by experts. The online survey results revealed that the majority of teachers found capacity building exclusively by the government through DIET very useful. However, during the next level of an indepth interview which lasted on an average for forty minutes, many 'tongue- incheek' responses were received stating that. "... the training was good, I attended it. Do I have a choice"? The data analysis was done using framework approach which involves recurring and repeated reading of the transcript to identify the underlying themes, the data was rearranged in excel sheet, and against each theme/sub-theme, each teacher's entries were coded and categorized with a frequency of pattern in similar texture or meaning (Ritchie \& Spencer, 2002). For ease of further interpretation and analysis of data, the transcribed data included "rich, thick descriptions" with "adequate engagement (of the researcher) in data collection" strategies to arrive at meaningful, candid and data-based inferences (Merriam, 2009). While the in-depth interview was conducted, detailed verbatim 
notes (in Marathi) were taken by the researcher also documenting the non verbal cues (Creswell 2012) as the researchers noticed signs of enthusiasm, pauses, masking, sarcasm, spontaneity or caution in their responses.

\section{Findings and Discussion}

The data collected from the teachers were collated and analyzed. The analysis of data revealed four broad categories on what teachers considered as effective capacity building programs for them. In the table below the first column enlists broad categories and themes emerging from teachers' views on effective professional development. The second and third columns capture their views on strengths, areas of improvement and suggestions for way forward for the PPP based capacity building. Due to the limitation of space for this paper, subthemes are not discussed. This article only presents the analysis of the teacher's perception of PPP and does not include the more extensive comparative analysis with DIET training as the objective of this study was to identify the teacher's perception of the PPP based training program. The results have been summarized in the table below:

Table 1. Summary of findings on teacher perception

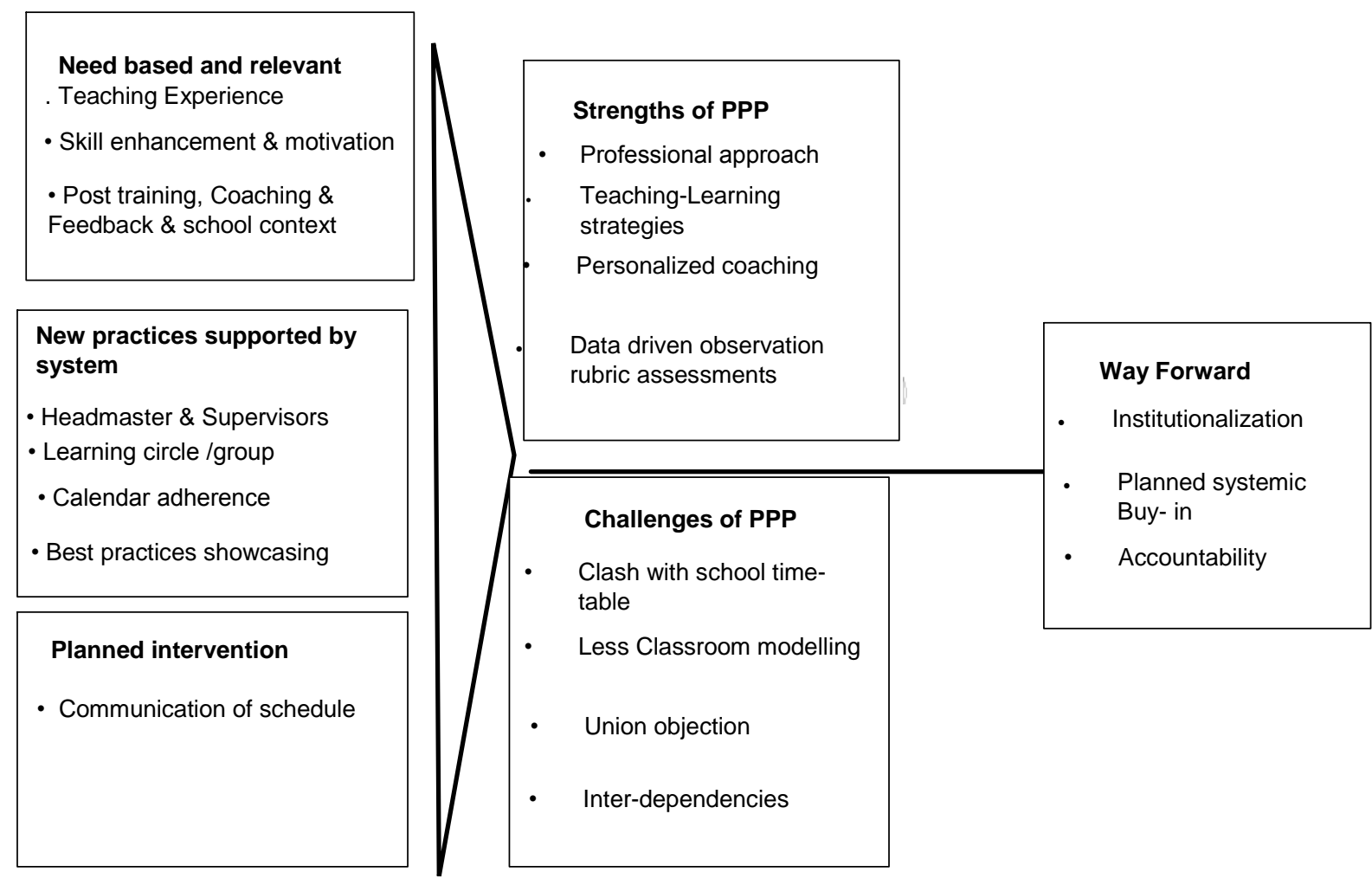




\subsection{Research question one: What is effective capacity building according to teachers?}

\section{1 (a) Need -based and relevant}

Most of the teachers stated that according to them the capacity building is effective if the topic, content, and methodology is as per their specific learning needs:

\section{1 (a) 1. Teaching Experience}

Among the senior teachers who have ten plus years of teaching experience and exposure to training over the years $(15,30 \%)$,most of the teachers voiced that their learning needs were different than those of new teachers, for instance, a verbatim of one (T14)was, "I am fifty years old and joined when I was twenty, so I already have sufficient experience of teaching, and at this time according to me effective capacity building should be subject-specific and not merely a motivational training.: Another senior teacher (T9)with over fifteen years' experience opined that" Attending random training programs is not my idea of capacity building, it may be a checklist item for authorities, profession for NGOs and compliance for us but not valueadding, effective capacity building should take me forward from where teacher is at the given moment, if I talk for myself then I find the refresher courses repetitive and monotonous, and only when we get a program on new ways of teaching, I learn a lot." The experienced teachers' views were similar to the study conducted by FeimanNemser (2001) which highlighted the link of capacity building with the phase of teacher's career. Similarly, Huberman (1995) pointed out that the learning needs of a teacher are related to the stage of career. He classifies them as "career entry," then "diversification and change," followed by "stock-taking and interrogation," and finally "serenity" or "disengagement." Serenity is a function of the "life review" by teachers and if the teacher is not satisfied the same will be replaced with "disengagement" in the last phase of career (Huberman, 1995).Varied perspectives were shared on expected training matching experience even less experienced teachers also wanted more in-depth content training. The experienced teachers learning needs were different from those of novice teachers.

the videos.

\section{1 (a) 2. Skill enhancement and personal motivation}

Most of the teachers $(33,66 \%)$ shared that capacity building is effective if it leads to change in practice. For example, the teacher (T6) said, "In government schools, there are only children from poor families and as per RTE Act, every child between 6 to 14 years of age has to be compulsorily enrolled in an age-appropriate class. This is with or without prior schooling, so effective capacity building for me is to learn the differentiating strategies and optimize on thirty minutes duration of each period". Another teacher stated, "Capacity building is knowing 'how' in addition to understanding 'what.' Most training that we attend only focuses on what we need to do; they are good, but more recently, I like the program, which helps me with the skills." Teacher (T8) stated, "Effective capacity building is skill-building not trainers notes 
being transferred in my notes and then after the sermon, the trainer vanishes. I need to learn the application in class". The teachers categorically mentioned skill and learning of the process as an essential aspect of capacity building. The findings resonate with the expectations of the teachers highlighted by Joyce and Showers, 2002 and Hammerness et al. (2005) on the importance of skill learned during the in-service program through an iterative process of practicing and reflecting on the new skill learned. There were teachers $(28,56 \%)$ who attributed personal motivation or will to excel in their chosen field of teaching as the reason to attend all training programs with the belief that they will learn something. It is similar to the study by Feiman-Nemser (2001), pointing that the desire for teacher training depends on the teacher's perception, motivation, and attitude for self-development.

\section{1 (a) 3. Post- training expert coaching and feedback}

Teachers considered the capacity building program which closed the loop after the workshop through classroom modeling, observation, coaching, and feedback as effective. For instance, one teacher (T16) said, "I have attended many workshops and while it did seem to be important at that time, on the very next day once I was back to class routine everything was forgotten, however more recently I have been exposed to such training workshops where there is a mentor who observes my class and shares feedback, and there is gradual change in my practice." Another teacher (T5) stated, "I find effective capacity building when there is a modeling in my class, and when I see my students learning faster it motivates me to apply my learnings in class with a confidence that if I make a mistake, I will be given a constructive feedback after the class to understand areas of improvement." Learning from competent and expert trainers and coach's adept in both andragogy and pedagogy was the nutshell of the voices. One of them (T7)said that "If a trainer who has never taught children tells me how to teach or observes my class and only tells what I could have done better though I have to accept as that person has more knowledge of new innovative methods, but if not able to teach my students in class, then the feedback has no significant value to me." It is similar to the importance of handholding after the training highlighted by Garet et al. (2001) in their study of a national sample of American teachers.

\section{1 (a) 4 . School and community context}

One of the most significant aspects for effective capacity building for the teachers was the ability to the context relatable to their specific school, and community context, a teacher (T5) said: "My school is located in a violent community my classroom challenges are different and more than content training, I need classroom management strategies." Another teacher (T12)stated that" Parents of the children in our government schools are not educated, so their academic support at home is missing in student's holistic development, and effective capacity building for me would be an ability to loop in parents for their non-academic support." The findings matched with the description given by Fullan et.al. (2006) on "contextuallybased, personalized, data-driven instruction context" (Fullan, Hill \& Crevola, 2006). It is necessary for professional development to take into cognizance the specific school and personal context of teachers. The teachers said that when the 
school and community context were missing, they felt that the training was not relevant to them "nice to hear" but "not practical."

\section{1 (b) New practices to be supported by the system}

One of the most critical voices from teachers was the importance of systemic support for their capacity building. The following were the main perspectives:

\section{1 (b) 1. Headmasters and supervisors}

"An effective program for me would be when seniors in school hierarchy agree to the importance of training and support me in applying the new learnings in class," stated one teacher (T3) who also shared that it happened very rarely. Another teacher said, "Our role is to develop the students academically and also inculcate values; however, as we are also government servants and have to do other duties like election duty, census survey and our headmaster not his fault but requires us to do nonacademic, administrative work during school time. So, if we cannot even do justice with our syllabus when can we apply the learnings from training". Teachers felt that acknowledgment of incremental changes in practice from headmaster and Supervisors would be very motivating to apply the learning. It is because unlike private schools, the context of teachers and students is different in government schools, a teachers (T22) said. "we are always told that due to job security our teaching practice is poor, but another reality is that students are not at appropriate class level, so if I make small improvements in teaching practice some appreciation from authorities will motivate me to continue, but if the culture is more to complete the administrative work there is no reason to swim against the tide." Researchers have pointed out that educational changes have to be system-wide, the stakeholders (e.g., Levin \& Fullan, 2008; Wedell, 2013).It was evident from the data that one of the significant strengths or impediments for the effective implementation of any positive change in school is from the seniors within the system. The unsupportive system will quell the benefits from capacity building and the training would only remain a theoretical exercise. Sandholtz, J. and S. P. Scribener (2006), in their article 'The Paradox of Administrative Control in Fostering Teacher Professional Development,' highlight the importance of systemic support, which was reinforced by teachers views.

\section{1 (b) 2. Learning Circles/ Groups}

A few $(10,20 \%)$ teachers shared the need for an overall culture to learn, discuss, debate, divide among the peer groups, or teaching staff would be a great help. One of the teachers (T3) said, "Most of the time only one or two of us from my school are nominated at a time, and when those teachers come back feeling motivated, other teachers cannot relate to enthusiasm nor can they get any further input in the same direction from within the school. An effective program should have a mechanism to keep the tempo on from within the teachers who participate". Teachers stated that if they have a support group with whom they could share their challenges and get solutions, it will make the program far more effective and sustainable. There have been similar studies which highlight the need for teachers to participate in learning communities for in-depth learning (Putnam \& Borko, 2000). 


\section{1 (b) 3. Calendar adherence}

Almost all teachers $(42,94 \%)$ voiced the need to have flexibility in the school calendar. A teacher (T25) said, "if we take practice sessions, the supervisors who visit want us to follow the calendar strictly." A teacher (T4) quoted," while training is conducted after school hours or on holidays all the new teaching-learning practices like action learning or reading fluency classes need to be applied in school but if the school does not accommodate the existing calendar the three is not enough scope to practice." These findings are similar to an analysis of the ways in which the school leadership team can help in effective implementation of professional development of teachers including openness and flexibility to experiment, among other things (Loxley et al., 2007).

\section{1 (b) 4. Best practices showcasing}

The majority of teachers $(39,78 \%)$ in government schools reiterated the need for inspiration, role model, and motivation, which will be met by sharing that for capacity building to be effectively implementable. Incremental learnings incorporated in class should be showcased. Their perceptions correspond to the experience of Finnish teachers on the benefits of receiving appreciation (Jyrhämä, R, 2008). As one teacher (T1) said," it would serve two purposes, one if it is my best practice, I will feel acknowledged and motivated from peers and seniors and second it would inspire other teachers." Another teacher (T5) shared similar views stating, "unlike private schools, we do not have promotions or performance-linked appraisal and if the best practices are showcased it will be a motivator also to be one of the best." This is the problem of government school teachers since the jobs are permanent; they have no performance linked appraisal or promotion. The teachers feel that at least if their best practices are showcased, they will get some acknowledgment and limelight which alludes them as their training program of elementary education suffer from "isolation, low profile and poor visibility" (NCTE, 2009, p. 11).

\section{1 (c) Planned Intervention}

Many teachers $(30,60 \%)$ particularly commented that effective capacity building program should be a well -planned activity. They said that random programs are very inconvenient; however, content-rich they may be. The following were the verbatims on both the aspects of communication and involvement in design voiced by teachers. The findings were akin to the study highlighting the importance of methodological factors for the capacity building like process and procedure in addition to content and context (Villegas-Reimers, E., 2003; Terehoff I. I., 2002).As Terehoff, emphasizes that only through planning teachers will receive "rich opportunities" for learning along with "growth and self fulfillment." 


\section{1 (c) 1. Communication of schedule}

Most of the teachers $(32,64 \%)$ felt that whether it is a one-time workshop or a long intervention, a proper prior notification of the timeline and other commitments is a pre-requisite. The vocal teacher (T3) stated," I would prefer to know before the starting of next academic year as to what training will be imparted, when would it start, what would be the benefits and all other relevant details." The importance of "timely update" and regular information was emphasized by another teacher she said," We must show mutual respect as surprise announcements and especially of long- term duration change our existing teaching and personal schedule."

\section{1 (c) 2. Involvement from design to implementation}

For a useful capacity-building inclusion in design and overall plan was the felt need, most of whom were senior teachers $(28,56 \%$.) One senior teacher (T9) said," I can share the classroom context to make the design practical. So, for me, most programs seem theoretical with an outside-in view such inputs are needed, no doubt, but they should not remain just pleasant to listen but impractical to implement." Another teacher (T30) shared that, "I know the program comes from management and they can't ask each one of us however at least while implementing each one's context and inputs should be taken for better results." Frost et al. (2010) effectively highlight the importance of planning, mainly when a teacher training program is run through a collaboration.

\subsection{Research question two: What are the strengths and areas of improvement of PPP based training?}

When asked about the strengths and challenges of PPP as compared to regular government training programs on Marathi reading fluency, the following views were seen:

\section{2 (a) Strengths of PPP}

Most of the teachers $(37,74 \%)$ were thankful for the PPP training received and could experience the difference in comparison of regular training that they received directly without any private (PNGE) support:

\section{2 (a) 1. Professional approach}

The teachers invariably stated that PPP training was far more precise in terms of timelines, objectives, methodology, delivery, post-training support, etc. For example, one teacher (T20) said, "Apart from how to teach 'Marathi reading fluency', I also see the demonstrated punctuality, discipline, planning of resources, use of teaching aids, communication during PPP. I have learned positive ways of teaching discipline, accountability, and punctuality which I have started using with my students than shouting and scolding them." Another teacher (T17) added, "The teacher mentors are chosen from amongst us, and they are trained by (PNGEs), and when we see them 
demonstrating professional skills using PowerPoint presentations, flip charts, and other teaching aids effectively, we feel inspired to learn and practice the same." The use of various teaching aids and demonstrated professionalism was tremendous learning, according to teachers. The findings were similar to the importance of a professional approach to teacher development highlighted by Pitsoe, V. J et al. (2012) who emphasized the constructivist approach of giving teachers a choice to learn rather than only passive listening of rote -based training programs.

\section{2 (a) 2. Teaching-Learning strategies}

Teachers felt that PPP training had given them exposure to many teachinglearning strategies to reach students with different learning styles. On being interviewed one teacher( T 16) said," I used to only cater to the students who were below the class average, and the brighter students would feel bored and play mischief during the class, and when I would begin teaching them the others would lose connect and my grades used to be chaotic. The PPP on reading fluency has segregated the lower order reading skills as level 1, next level 2 and age-appropriate as level 3 and this has solved a lot of problems for me." Another teacher said (T37), "instead of only reading from books and writing on the blackboard, I have started bringing assignment sheets, newspaper cuttings, other material as trained by mentors, and it is a mutually engaging experience for students and me." One teacher (T12) said, "My creativity has been spurred as I think of innovative ways to teach and organize the available resources." The importance of how new teaching-learning strategies evolve, and the role of productive dialogue is also highlighted by Routman R. (2000) which is similar to the findings of this study where teaches also voiced that they appreciated the new strategies taught through PPP.

\section{2 (a) 3. Personalized coaching}

Teachers appreciated the mentoring support after every module completion to see the implementation in the class. A teacher (T27) said, "I await the day when the teacher mentor comes in my class, unlike other classroom observation where I feel judged as the observer sits with impassive expression and then goes away making me wonder what his/ her opinion was, this is one observation I cherish." Teacher (T18) said, "If I struggle with any aspect of applying the new learning, I know teacher mentor is there to guide and even my students await the teacher mentors as they have developed a bond with frequent visits. My practical challenges and struggles are known to my mentor." Another teacher (T4) shared, "When the training is over the onus of applying the new practices is on teacher earlier the trainers did not have any experience of teaching children; however, the teacher mentors trained by PNGEs have been picked up from among us so they understand students context which reduces the frustration of just listening to desirable but unpractical stuff. In government-run DIET training programs, there is no after the training handholding". Researchers have similarly pointed out that having an expert/ veteran coach, and observer for personalized goal setting and action is beneficial for teachers, rather than a one-time workshop (Martinez, M., 2019; Johnson, S. R.et al., 2016). 


\section{2 (a) 4. Data-driven rubric assessment}

Another exceptional feature of PPP based capacity building was the use of a data-driven rubric for assessment of teacher competency. One teacher (T23) said, "Our lessons are observed with the help of a rubric and after each session, our mentor gives us feedback." Another teacher (T42) said," The feedback is always constructive, and areas of improvement are shared with data in terms of teacher actions and student activities, and we are asked what would have been a better way than telling us down. This system has helped me reflect on my teaching practice and bring positive change where needed." There have been a lot of studies (e.g. Avalos, B., 2011; Kane T. J, et al., 2011) emphasizing the importance of data-based observation and assessment of practice, as Avalos has pointed this based on in his ten-year analysis of teacher capacity building.

\section{2 (b) Challenges of PPP}

Out of the fifty teachers interviewed $(29,58 \%)$ shared many challenges of the PPP model as well, which gives a more in-depth explanation of why despite two years of PPP National Achievement Survey (NAS) 2017 reveals that students in this city of research study have lower (less than age-appropriate) reading levels compared to others in India. The perceptions have been clubbed in given categories.:

\section{2 (b) 1. Clash of timetable}

Teachers found the clash in time-table of reading fluency class with earlier timetable an impediment. One teacher (T31) said, "Since the order comes from top to attend the program, we only follow it however if the PNGE intervened program requires changes in time table only top layers permission guarantees attendance but other levels have to agree and just getting an order to that effect leads to challenges. Another teacher (T7) said, "Only a short duration class is given for Marathi reading fluency, which should be ideally longer duration and I have to send level-wise students to other class and receive students from other class in my class for the level I am teaching example level 3. This shuffling takes away a good ten minutes of the thirty minutes duration. Children take five minutes to settle down and align with the topic." Another teacher (T4) said, "I do not like to send my students to other classes rather with differentiating strategies learned. I want to plan the thirty minutes for all the three levels of reading for my students; however, this PPP model does not give us flexibility." Though it seems to be a small problem, the rigidities of the system, coupled with rigidities of models, create a lot of difficulties, which was also seconded through interviews of PPP teacher mentors. As stated by Terehoff, I. I. (2002), planning is essential for the success of professional development. In the case of PPP despite thorough planning by PNGE partner the rigidities of the school calendar lead to a change of plan or clash of timetable as stated by teachers. 


\section{2 (b) 2. Less classroom modeling}

One of the shortcomings of PPP was that the teacher mentors trained, observed class and gave feedback but had no classroom modeling. One teacher (T32) said, "the mentors are handpicked from among us and trained by PNGEs as part of PPP, so we need to see how they would teach differently. Initially, they did not model a lesson plan in class at all, but during the quarterly feedback, we shared this concern and as a response, they have begun modeling which is value-adding but not adequate." Another teacher (T18) said, "Since teaching us is comparatively easier as compared to teaching students we prefer class modeling, and this is an area which is not very effective in PPP." PNGE partners also stated the same which was used for deeper understanding and triangulation of data for analyses, and it was clear that andragogy (training adults) and pedagogy (teaching children) are two different skills and after receiving quarterly feedback, the mentor teachers who had been teachers earlier were through course correction trained to model the lesson in class; however, the class modeling was not enough. As pointed by Pitsoe, V. Jet al. (2012) the professional development should not only be "sustained, ongoing, intensive" it should also be "supported by modeling." This observation and feedback of teachers for PPP are very crucial.

\section{2 (b) 3. Union objection}

The union objects to any private or NGO interference fearing privatization and resisting interference. A teacher (T22) said, "Our Union instructed us to ban PPP training, it was sad as the training was beneficial and yet we had to succumb to the pressure for a while. However, thankfully they allowed us to attend later but they are still against any third party(external)observation of classroom practices." Another teacher (T49) said, "In my cluster, all the schools had to ban PPP training for a longer time as compared to other clusters. It was done unofficially due to the presence of many union teachers in our cluster. Union resists because though teacher mentors are from within the government school system, they are trained by PNGEs. After a lot of discussion and directives from the top, the training resumed but a lot of time was wasted." Teacher union is against the PNGEs influence in government schools. Three of the teachers interviewed were from the union, and they shared that they fear "privatization" of government schools and object to PNGEs imposing any rules, routines, and structures. They also do not allow third-party assessment of teacher training or student learning level assessment from outside. For the future success of PPP, a dialogue with the union is also necessary. The objection from teacher union is not new in research across time and geographies (for e.g. Gaynor C, 1998; Adams A.et al., 2005) have also discussed this longstanding tussle. Therefore, it is essential to find a way to harness the Union's energy constructively.

\section{2 (b) 4. Interdependencies}

The interdependencies of government and PNGEs to leverage strengths is not without challenges as PNGES have to take fast action, and decision making is slow and bureaucratic in government schools. Teacher (T16) shared, "Many a time when I have a PPP training, a letter is received for all teachers to report for some other program by the administrative officer. There are too many interdependencies. 
Another teacher (T3) shared, "I feel that PPP should be allowed to adhere to their plan but due to many official and non-official work requirements either some or all teachers request for change of schedule'. This is one of the biggest challenges, the same was highlighted by PNGE partners and teacher mentors who reiterated that there has to be "mutual accountability "along with "joint ownership" of PPP capacity building. The views were similar to the findings of Acar, Metal. (2004) concerning PPP interdependencies in the US. In their recent study of the need for PPP in the Nigerian school context (Oyewole, 2016) highlighting the intricacies of public-private partnership nexus. There is a need to demarcate the responsibilities in PPP for sustenance (Bajwa, S. U, et al.,2018).

\subsection{Research question three: What is the way forward for PPP training?}

\section{3 (a) Way Forward}

When teachers were asked about the way forward, only $(20,40 \%)$ teachers shared their views, and the remaining teachers more or less had the same opinion that the ongoing program was excellent and should continue in the same way. The themes on suggestions were:

\section{3 (a) 1. Institutionalization}

The teachers said that new learning practices usually continue only while the 'NGO' support exists and forgotten after that, however since they found this PPP model unique with their teachers as mentors, they spoke about institutionalization. One of the teachers (T29) said," We hope to have a teachermentor system as a continued way and not as a fad which will come and go. If this method of strengthening our teaching practices stays, we will benefit consistently and not for this one reading fluency program." Another teacher (T10) said, "this level-wise progression to teach Marathi reading taught by PPP should continue for students so that poor reading levels which are less than age-appropriate will no longer be a problem in government schools." If, after the PPP tenure, the cadre of teacher mentors is

dissolved, it would be just an experiment and the resources time and expertise in training the mentors by PNGEs would be lost. This PPP helps develop an internal cadre of teacher mentors and it is the first time that for the capacity building of teachers government and PNGE's are working at a large scale with joint ownership, the teachers' perception based on their experience of other NGOs forgotten efforts is an essential indication of the need to institutionalize the process. The failure of institutionalization in PPP is succinctly dealt with by Kumar, K. (2008), where he says that it only leads to joint ownership but does not allocate tasks or institutionalize the learnings.

\section{3 (a) 2. Planned systemic buy-in}

A few teachers felt that while PPP was much more professional teachers, they thought that any program however good, should be intimated at least in the previous year. Also, all stakeholders including HM, supervisors, union, parents, students, should be aware of and co-own the process. A teacher (T5) said, "In the 
past, many NGOs conducted sessions directly with students, a few gave us free resources, and they could reach a limited school for a short while, hope this is going to be different and long term." Another teacher(T44) said, "This PPP is different as the teacher members are selected teachers from within our school system; all we need is blessings from seniors to implement the new learnings. Our success will largely depend on support from our seniors in the system." Earlier, various NGOs have worked in few schools by only taking the permission of the school headmaster. However, when the NGO withdrew support, the changes brought by them were forgotten due to no systemic buy-in from the education department, supervisors, local politicians, or other stakeholders in the system. In his in-depth paper on PPP Paradox, Gopalan, P. (2013) has also pointed out the perils of not getting the systemic buy-in.

\section{3 (a) 3. Accountability}

Another important theme that most teachers shared (though in undertones) was two-way accountability. One teacher (T30) said, "We are learning how to optimize the time with students by addressing students from all reading levels, it would be nice if our administrative workload is exempted on the day of training, we should not be called back for any official work." Another critical recommendation from one teacher (T26) was, "when three teachers share one level each (among 1,2,3) while teaching reading fluency, each one should teach the students from other classes sincerely and this does not always happen. Without ownership and accountability from all teachers, the reading level in each category will forever remain skewed. The teachers spoke about the accountability of their peers to teach with same sincerity and almost all of them said that they were saddled with administrative work, the PNGE partners implored on the accountability of government stating that even when there is transfer of senior officials the practice should continue seamlessly without a change in schedule or planned commitment. Most teachers said that at the last minute, the administrative officer of their respective cluster sends an order to them to attend another meeting instead of PPP training scheduled on that day, which they cannot refuse. It is similar to the paper on the futility of PPP by Kumar K (2008), where he argues that to increase the efficiency of government more inefficiency is generated; authority remains the same, but accountability towards the work is given to non -government partner.

\section{Conclusions and Recommendations}

This study highlights the importance of teachers' voices; hence we recommend that instead of idolizing, patronizing or criticizing the teachers, their views should be duly taken into consideration before any change intervention in schools. The study reveals the bureaucratic and systemic nexus within the educational eco-system. The researchers caution that it is not enough to only subject the teachers to a multitude of programs as a captive audience and they recommend the availability of options like lengthy or modular or granular programs that are not one size fits for all (Diaz-Maggioli, G. 2003). The study also revealed that there is very less focus on teachers as the co-authors of their own professional development and therefore, there is a need to assimilate their 
views, assess their needs, perceptions and elicit their active involvement from design to the implementation phase of capacity building through PPP. Teachers found PPP based training far more effective and professional than regular training by the government. The lack of policy on systemic support on teaching -learning practices (Knapp, 2003) are evident in this PPP based initiative and there should be a periodic review of trainings conducted and class room implementation without any bureaucratic hinderances. The accountabilities should be co-owned by both the partners otherwise, this intervention, may also be forgotten. Since this PPP is already operational at a scale in the last two years, with optimum results of capacity building this model can potentially be replicated in other districts. Based on this study of government school teachers, inputs from teacher mentors, PNGEs, DIET trainers working at the ground level, the researchers recommend that along with capacity-building efforts, the teacher selection, assessment, and accreditation standards of government schools need to be revamped. The study reveals a need to committedly drive one change at a time. The research is also a pointer to Local government to prohibit arbitrary orders to not allow teachers to attend pre-planned PPP training. PNGEs face resistance from teacher union members who do not even allow a third-party assessment of their teaching practice. A constructive dialogue with union teachers is recommended, as, few union teachers who were interviewed had unaddressed grievances and feared privatization. Therefore, taking them on board is required with a demarcation of responsibilities, to pave the way for a seamless and impactful PPP training.

\subsection{Limitations of the study}

Due to the space limitation the present study does not provide a comparative analysis of the perceived relevance of teachers for the government's DIET training with PPP based training and therefore may seem to be unidimensional.

\subsection{Directions for future research}

Researchers hope that this study would help policy makers, educationists, PNGEs and future researchers to delve deeper into real issues from ground for sustainable improvement in capacity building endeavors. The findings could be used to foster the advocacy for deep-rooted policy changes and pave way for more research on How best to build the teachers capacity with systemic involvement? Whose onus is capacity building of government school teachers? Should mutual accountabilities in PPP be defined perfunctorily by MOU as present scenario or be prescribed by policy or should the partnership be a project management exercise transacted professionally?

Finally, this paper recommends the PPP stakeholders to synergize their respective strengths of 'Elephant' (government) and 'Horse' (PNGEs); otherwise, the differences may lead to unsustainable results. 
Notes:

1. NCF1: the National Curriculum Framework for Teacher Education (NCFTE) 2009 is a government entity to suggest changes for the National Council for Teacher Education (NCTE)

2. NUEPA2: National University of Educational Planning and Administration (NUEPA) was established towards the universalization of quality education.

3. NPE3: National Policy of Education $\left(\mathrm{NPE}^{3}, 1986\right)-$ As per Wikipedia, The National Policy on Education (NPE) is formulated by the government to promote education. The successive policies are applicable for elementary education to colleges in both rural and urban India. Recently draft NPE 2019 has also been published.

4. PISA4- Programme for International Student Assessment (PISA), is the international scholastic test for students introduced by the Organization for Economic Cooperation Development (OECD) once in three years. India ranked $72^{\text {nd }}$ among the 74 countries that participated in 2009.Since then there has been a reluctance to participate in PISA.

5. ASER ${ }^{5}$ (Annual Status of Education Report), is an annual survey to conduct learning levels of students since 2005. The students from the $5^{\text {th }}$ standard in government schools, who were able to read $2^{\text {nd }}$ standard book has been around $41.1 \%$ in successive years. The latest ASER 2018 reveals a slightly higher $44.2 \%$ of the standard five students can read 2 nd standard book which is not commendable.

\section{References}

Acar, M., \& Robertson, P. J. (2004). Accountability challenges in networks and partnerships: Evidence from educational partnerships in the United States. International Review of Administrative Sciences, 70(2), 331-344. https:// doi.org/10.1177/0020852304044260

Adams, A., \& Tulasiewicz, W. (2005). The Crisis in Teacher Education: A European Concern? Routledge. https://doi.org/10.4324/9780203973837

Anuradha D., Noronha, C., \& Samson, M. (2002). Private Schools for Less Privileged: Some Insights from a Case Study. Economic and Political Weekly, 37(52), 52305236.

Avalos, B. (2011). Teacher professional development in teaching and teacher education for over ten years. Teaching and teacher education, 27(1), 10-20. https:// doi.org/10.1016/j.tate.2010.08.007

Bajwa, S. U., Kitchlew, N., Shahzad, K., \& Rehman, K. U. (2018). Public-Private Partnership (PPP) as an interdependent form (I-Form) organization. International Journal of Public Administration, 41(11), 859-867. https://doi.org/10.1080/01900692.2017.1298610

Batra, P. (2005). Voice and agency of teachers: Missing link in national curriculum framework 2005. Economic and Political Weekly, 4347-4356.

Bolam, R. (2002). Professional development and professionalism. In T. Bush \& L. Bell (Eds.), The principles and practice of educational management (pp. 103-118). London: Paul Chapman. https://doi.org/10.1007/978-1-4020-8186-6_10

Bransford, J., Darling-Hammond, L., \& LePage, P. (2005). Introduction. In L. DarlingHammond \& J. Bransford (Eds.), Preparing teachers for a changing world: What 
teachers should learn and be able to do (1-39). San Francisco: Jossey-Bass. https://doi.org/10.5860/choice.43-1083

Cole, A., \& Knowles, G. (2000). Researching Teaching: Exploring Teacher Development Through Reflexive Inquiry. Toronto: Allyn and Bacon.

Collinson, V., Kozina, E., Kate Lin, Y., Ling, L., Matheson, I., Newcombe, L., \& Zogla, I. (2009). Professional development for teachers: a world of change. European journal of teacher education, 32(1), 3-19. http://dx.doi.org/10.1080/02619760802553022

Contractor, F. J., Kumar, V., \& Dhanaraj, C. (2015). Leveraging India: Global interconnectedness and locational competitive advantage. Management International Review, 55(2), 159-179. https://doi.org/10.1007/s11575-015-0239

Cresswell, J. W. (2012). Planning, conducting, and evaluating quantitative and qualitative research. Educational Research. https://doi.org/10.4135/9781483349435.n10

Darling-Hammond, L., \& Richardson, N. (2009, February). Teacher learning: What matters? Educational Leadership, 46 - 53.

Diaz-Maggioli, G. (2003). Professional development for language teachers. Eric Digest, 03-03

European Commission. (2000). European Report on Quality of School Education: Sixteen Quality Indicators. Brussels: Directorate-General for Education and Culture.

Feiman-Nemser, S. (2001). "From Preparation to Practice: Designing a Continuum to Strengthen and Sustain Teaching." Teachers College Record 103: 1013-1055. https://doi.org/10.1111/0161-4681.00141

Fletcher, C. L., \& Barufaldi, J. P. (2002). Evaluating professional development with student data: Challenges and successes for project EST. Paper presented at the Annual Meeting of the National Association of Research in Science Teaching, New Orleans, LA.

Fullan, M. (2006). The future of educational change: System thinkers in action. Journal of Educational Change, 7, 113-122. Fullan, M., Hill, P., \& Crevola, C. (2006). Breakthrough. Thousand Oaks, CA: Corwin Press.

Garret, M. S., Porter, A. C., Desimone, L., Birman, B. F., \& Yoon, K. S. (2001). What makes professional development effective? Results from a national sample of teachers. American Educational Research Journal, 38(4), 915e945. https:// doi.org/10.3102/00028312038004915

Gaynor, C. (1998). Decentralization of education: Teacher management. The World Bank. https://doi.org/10.1596/0-8213-3810-2

Gopalan, P. (2013). PPP paradox: Promise and perils of public-private partnership in education. SAGE Publications India. https:// doi.org/10.1111/aeq.12089

Hammerness, K., Darling-Hammond, L., Bransford, J., Berliner, D., Cochran-Smith, M., McDonald, M., et al. (2005). How teachers learn and develop. In L. DarlingHammond \& J. Bransford (Eds.), Preparing teachers for a changing world: What teachers should learn and be able to do (pp. 358-389). San Francisco: Jossey-Bass

Huberman, M. (1995). Professional careers and professional development: Some intersections. In Guskey, T. \& Huberman, M. (Eds.) (1995) Professional Development in Education: New Paradigms and Practices. New York: Teachers College Press

James, K. S. (2008). Glorifying Malthus: Current debate on' demographic dividend' in India. Economic and Political Weekly, 63-69.

Johnson, S. R., Pas, E. T., \& Bradshaw, C. P. (2016). Understanding and measuring coach-teacher alliance: A glimpse inside the 'black box'. Prevention Science, 17(4), 439-449. https://doi.org/10.1007/s11121-016-0633-8 
Joyce, B., \& Showers, B. (2002). Student achievement through staff development. Alexandria, VA: Association for Supervision and Curriculum Development.

Jyrhämä, R., Kynäslahti, H., Krokfors, L., Byman, R., Maaranen, K., Toom, A., \& Kansanen, P. (2008). The appreciation and realization of research-based teacher education: Finnish students' experiences of teacher education. European Journal of Teacher Education, 31(1), 1-16. https:// doi.org/10.1080/02619760701844993

Kane, T. J., Taylor, E. S., Tyler, J. H., \& Wooten, A. L. (2011). Identifying effective classroom practices using student achievement data. Journal of Human Resources, 46(3), 587-613. https:/ / doi.org/10.3368/jhr.46.3.587

Kirby, S. N., McCombs, J. S., Barney, H., \& Naftel, S. (2006). Reforming teacher education: Something old, something new. Santa Monica: RAND. https://doi.org/10.1037/e654672010-001

Knapp, M. S. (2003). Chapter 4: Professional development as a policy pathway. Review of research in education, 27(1), 109-157.

Kothari, D. S., \& Chairman, A. R. (1967). Report of the Education Commission 1964-66. New Delhi, National Council of Educational Research and Training

Kumar, K. (2008). Partners in education? Economic and Political Weekly, 8-11.

Levin, B., \& Fullan, M. (2008). Learning about system renewal. Educational management $\begin{array}{lll}\text { administration } & \mathcal{E} & \text { leadership, 36(2), 289-303. }\end{array}$ https:// doi.org/10.1177/1741143207087778

Little, J. W. (1993). Teachers' professional development in a climate of educational reform. Educational evaluation and policy analysis, 15(2), 129-151. https:// doi.org/10.3102/01623737015002129

Loxley, A., Johnston, K., Murchan, D., Fitzgerald, H., \& Quinn, M. (2007). The role of whole-school contexts in shaping the experiences and outcomes associated with professional development. Journal of In-Service Education, 33(3), 265-285. https:// doi.org/10.1080/13674580701487034

Martinez, M. (2019). Personalization turns learning into a journey. The Learning Professional, 40(4), 9-12.

Menter, I., Hulme, M., Elliot, D., Lewin, J., Baumfield, V., Britton, A., ... \& Patrick, F. (2010). Literature review on teacher education in the 21st century.

Merriam, S. B. (2009). Qualitative research: A guide to design and implementation (3rd ed). San Francisco, CA: Jossey-Bas

OECD. (2005). Teachers matter: Attracting, developing and retaining effective teachers. Overview. Retrieved from https://doi.org/10.1787/9789264018044-sum-ja

Ormston, R., Spencer, L., Barnard, M., \& Snape, D. (2014). The foundations of qualitative research. In J. Ritchie, J. Lewis, C. Nicholls \& R. Ormston (Eds.), Qualitative Research Practice: A Guide for Social Science Students and Researchers (pp. 1-25). Los Angeles: Sage.

Oyewole, B. K., \& Osalusi, F. M. (2016). Towards actualizing and sustainable education standards in Nigeria. International Journal of Learning, Teaching and Educational Research, 15(9), 44-54.

Pitsoe, V. J., \& Maila, W. M. (2012). Towards constructivist teacher professional development. Journal of Social Sciences, 8(3), 318-324.

Putnam, R. T., \& Borko, H. (2000). What do new views of knowledge and thinking have to say about research on teacher learning? Educational researcher, 29(1), 4-15. https://doi.org/10.3102/0013189x029001004

Rath, S. K., \& Bhagavan, B. (2014). Implications of Skill Incongruity on Leveraging India's Demographic Dividend. International Journal of Humanities and Social Science Invention, 3(4), 26-35. 
Ritchie, J., \& Spencer, L. (2002). Qualitative data analysis for applied policy research. In Analyzing qualitative data (pp. 187-208). Routledge. https://doi.org/10.4324/9780203413081_chapter_9

Routman, R. (2000). Conversations: Strategies for Teaching, Learning, and Evaluating. Heinemann, 361 Hanover Street, Portsmouth, NH 03801-3912.

Sandholtz, J. H., \& Scribner, S. P. (2006). The paradox of administrative control in fostering teacher professional development. Teaching and Teacher Education, 22(8), 1104-1117. https://doi.org/10.1016/j.tate.2006.07.006

Shymansky, J. A., Yore, L. D., Anderson, J. O., \& Hand, B. M. (2001). Teacher beliefs about, perceived implementation of, and demonstration classroom use of science reform principles. Paper presented at the meeting of the National Association for Research in Science Teaching, St Louis, MO.

Snape, D., \& Spencer, L. (2003). The foundations of qualitative research In J. Richie \& J. Lewis (Eds.), Qualitative Research Practice (pp. 1-23). Los Angeles: Sage

Stringer, E. T. (2008). Action research in education. Upper Saddle River, NJ: Pearson Prentice Hall.

Taylor, S. J., \& Bogdan, R. (1998). Introduction to qualitative research methods: A guidebook and resource. (3rd ed.). New York: Wiley. https://doi.org/10.1177/089124167700600206

Terehoff, I. I. (2002). Elements of adult learning in teacher professional development. NASSP Bulletin, 86(632), 65-77. https://doi.org/10.1177/019263650208663207

Turner-Bisset, R. (2001). Expert Teaching: Knowledge and Pedagogy to Lead the Profession. London: David Fulton Publishers. https://doi.org/10.4324/9781315068961

UNESCO. (2013). Intercultural competence: Conceptual and operational framework. Paris: UNESCO, Section of Education for Peace and Human Rights, Division of Education for Peace and Sustainable Development, Education Sector. Retrieved from http:// unesdoc.unesco.org/images/0021/002197/219768e.pdf.

Villegas-Reimers, E. (2003). Teacher professional development: an international review of the literature. Paris: International Institute for Educational Planning.

Webster-Wright, A. (2009) Reframing Professional Development Through Understanding Authentic Professional Learning. Review of Educational Research, 79/2, 702-739. (TCP). https:// doi.org/10.3102/0034654308330970

Wedell, M., \& Lamb, M. (2013). Portraits of inspiring English teachers in China and Indonesia. British council. 